\title{
COMMENTARY
}

\section{The cellular receptor for enterovirus 71}

\author{
Yue Liu, Michael G. Rossmann ${ }^{\bowtie}$ \\ Department of Biological Sciences, Purdue University, West Lafayette, IN 47907, USA \\ $\square$ Correspondence: mr@purdue.edu (M. G. Rossmann)
}

The Picornaviridae family consists of a large group of nonenveloped, icosahedral viruses with a single, positivestranded RNA genome. The family includes pathogens that are notable for a variety of human and animal diseases (Racaniello, 2007). Picornaviruses initiate infections by attachment to host cell receptor molecules and then undergo uncoating to release the viral genome into the cytosol for replication (Racaniello, 2007). The enterovirus (EV) genus is perhaps the most intensively studied genus among the 26 known genera.

X-ray crystallography (Hogle et al., 1985; Rossmann et al., 1985), cryo-electron microscopy (cryo-EM) (Olson et al., 1993; Bubeck et al., 2005b) and molecular biology have unraveled some of the molecular mechanisms of EV cell entry (Tuthill et al., 2010). Specifically, a canyon-like cleft on the surface of the virus encircling each pentameric vertex is frequently the binding site for putative cellular receptors whose structure belongs to the immunoglobulin superfamily (Table 1) (Rossmann et al., 2002). When these receptor molecules bind into the "canyon" of the EVs, the "pocket factor", a fatty acid-like molecule residing in a hydrophobic pocket underneath the "canyon", is ejected (Rossmann, 1994; Xiao et al., 2005; Xiao et al., 2011). This destabilizes the virus and triggers the uncoating process leading to the formation of uncoating intermediate $A$ particles (Rossmann et al., 2002; Bubeck et al., 2005a; Zhang et al., 2008). When a receptor binds into the canyon, the base of the canyon is depressed towards the center of the virus thus diminishing the size of the pocket that contains the pocket factor, causing the stabilizing pocket factor to be ejected. This happens because the peptides forming the base of the canyon also form the roof of the pocket. Thus, in essence, either the receptor or the pocket factor can bind to the virus, but not both (Smith et al., 1986; Rossmann, 1989). However, receptors to some EVs, such as the minor group rhinoviruses, bind to other locations on the viral surface and don't assist in viral uncoating (Table 1) (Plevka et al., 2010; Tuthill et al., 2010; Shakeel et al., 2013).

Human enterovirus 71 (EV71) is currently a major causative agent for hand, foot and mouth disease with occasionally severe neurological complications. A growing number of
EV71 outbreaks have been reported in the Asia-Pacific area since the late 1990s raising considerable public health concerns (Yip et al., 2013). Two transmembrane proteins, human PSGL-1 (P-selectin glycoprotein ligand-1) and human SCARB2 (scavenger receptor B2), have been identified as the functional receptors for EV71 (Nishimura et al., 2009; Yamayoshi et al., 2009). Unlike human PSGL-1, human SCARB2 is expressed in a wide range of tissues, including neurons in the central nervous system, and functions as a receptor for all tested EV71 strains. More importantly, human SCARB2 not only binds to EV71 but induces EV71 uncoating in a low pH environment (Yamayoshi et al., 2013), which is consistent with the finding that endosomal acidification is essential for EV71 infection (Lin et al., 2012). SCARB2 has a novel fold with a twisted $\beta$-barrel core (Neculai et al., 2013). It appears that residues 144-151 of a three-helix bundle at the head region of human SCARB2 are directly involved in EV71 binding according to two independent studies (Yamayoshi and Koike, 2011; Chen et al., 2012). Nevertheless, there is some uncertainty whether there are also other residues involved in virus attachment. Thus the human SCARB2dependent uncoating of EV71 remains enigmatic.

Dang et al. now present structural and functional studies of human SCARB2 (Dang et al., 2014). Human SCARB2 structures at both neutral and acidic conditions were determined by X-ray crystallography, showing a pH-dependent conformational change of the three-helix bundle. Structural comparisons indicate that the helical bundle acts as a "cap" that regulates the accessibility of the entrance to a large cavity which traverses the whole length of the ectodomain and might be a lipid-transfer tunnel.

Recombinant human SCARB2 was shown to facilitate the expulsion of sphingosine (a pseudo-pocket factor) from EV71 saturated with radioisotope labelled sphingosine under acidic conditions. Furthermore, the transition of native EV71 to A particles on binding SCARB2 demonstrated that EV71 undergoes uncoating upon incubation with human SCARB2 in a low $\mathrm{pH}$ environment. In vitro binding assays, employing synthetic peptides together with in silico docking, suggested the three-helix bundle binds to the EV71 "canyon" and that the entrance of the putative lipid-transfer tunnel is in 
Table 1. Selected enteroviruses and their cell entry characteristics

\begin{tabular}{|c|c|c|c|c|}
\hline Virus & Receptor & Receptor structural feature & Binding site on virus & $\begin{array}{l}\text { Initiation of } \\
\text { uncoating }\end{array}$ \\
\hline Poliovirus 1-3 & CD155 & Ig-like & Canyon & Yes \\
\hline Coxsackievirus A21 & ICAM-1 & Ig-like & Canyon & Yes \\
\hline Major group rhinoviruses & ICAM-1 & Ig-like & Canyon & Yes \\
\hline Coxsackievirus B3 & CAR & Ig-like & Canyon & Yes \\
\hline Coxsackievirus A9 & Integrin $\alpha v \beta 6$, $\alpha v \beta 3$ & V-shaped, 12 domains & Near two-fold axes & No \\
\hline Echovirus 7 & CD55 & Four short consensus repeats & Near two-fold axes & No \\
\hline Minor group rhinoviruses & LDLR family & $\begin{array}{l}\text { "arc"-like arrangement of ligand } \\
\text { binding domain repeats }\end{array}$ & $\begin{array}{l}\text { Shallow pits near } \\
\text { five-fold axes }\end{array}$ & No \\
\hline
\end{tabular}

The table is based on observations by Rossmann et al., (2002), Plevka et al., (2010), Tuthill et al., (2010) and Shakeel et al., (2013). ICAM-1 intercellular adhension molecule 1, CAR coxsackievirus and adenovirus receptor, LDLR low density lipoprotein receptor.

proximity to the hydrophobic pocket underneath the "canyon" at neutral $\mathrm{pH}$. Taken together, these findings offer a novel model for human SCARB2-dependent cell entry of EV71 in which human SCARB2 serves as a molecular switch that aids in the expulsion of the pocket factor and triggers EV71 uncoating upon acidification.

The expulsion of the labelled sphingosine by binding of SCARB2 supports the suggestion that the receptor binds into the canyon as proposed by Dang et al. Hence, an alternative explanation of the above observations is that binding of SCARB2 expels the pocket factor and destabilizes the virus in much the same way as the other receptor molecules that are known to bind into the canyon of EVs.

Another aspect of the study by Dang et al. is that acidinduced conformational change of the "cap" region might be a common basis for $\mathrm{pH}$-dependent interactions of SCARB2 with its ligands including both EV71 (an exogenous ligand) and $\beta$-glucocerebrosidase ( $\beta-G C$, an endogenous ligand), as SCARB2 was known to deliver $\beta-G C$ from the endoplasmic reticulum to lysosomes (Zachos et al., 2012). Thus it would be interesting to determine which residues are important for the $\mathrm{pH}$-induced structural changes and whether substitutions of these residues would impair the ability of SCARB2 to trigger EV71 uncoating and transport $\beta-G C$. More importantly, SB-RI and CD36, which are homologous to SCARB2, have so far been shown to transport cholesterol and fattyacids, respectively (Neculai et al., 2013). SCARB2, however, hasn't been demonstrated to possess the ability of binding and/or delivering lipid despite containing a large cavity that might accommodate lipid ligands. Therefore, the functional importance of this large cavity remains to be further characterized.

Although Dang et al. have made some interesting suggestions regarding the interaction of EV71 with human SCARB2, there are still many other questions that need to be answered. For instance, does human SCARB2 induce the uncoating in other viruses that can interact with SCARB2 such as coxsackievirus A7, A14 and A16 (Yamayoshi et al., 2012)? If yes, would the acid-triggered conformational change be a major factor for the uncoating of these viruses? Is it possible to design agents that interfere with the $\mathrm{pH}$ dependent conformational change of SCARB2 or bind to the presumable lipid-transfer tunnel? Can these agents be selectively designed so as to inhibit EV71 and other related viruses without affecting the normal function of SCARB2 in host cells?

In summary, the work by Dang et al. provides a new model for receptor-mediated entry of picornaviruses into host cells that depends on the $\mathrm{pH}$-triggered conformational change of the receptor molecule. The detailed molecular basis of the interaction between EV71 with human SCARB2 and the functional importance of the large cavity within SCARB2 still remains open questions for future studies.

\section{COMPLIANCE WITH ETHICS GUIDELINES}

Yue Liu and Michael G. Rossmann declare that they have no conflict of interest.

\section{OPEN ACCESS}

This article is distributed under the terms of the Creative Commons Attribution License which permits any use, distribution, and reproduction in any medium, provided the original author(s) and the source are credited.

\section{REFERENCES}

Bubeck D, Filman DJ, Cheng N, Steven AC, Hogle JM, Belnap DM (2005a) The structure of the poliovirus $135 \mathrm{~S}$ cell entry intermediate at 10-angstrom resolution reveals the location of an externalized polypeptide that binds to membranes. J Virol 79:7745-7755

Bubeck D, Filman DJ, Hogle JM (2005b) Cryo-electron microscopy reconstruction of a poliovirus-receptor-membrane complex. Nat Struct Mol Biol 12:615-618

Chen P, Song Z, Qi Y, Feng X, Xu N, Sun Y, Wu X, Yao X, Mao Q, Li $X$ et al (2012) Molecular determinants of enterovirus 71 viral entry: cleft around GLN-172 on VP1 protein interacts with 
variable region on scavenge receptor B 2. J Biol Chem 287:6406-6420

Dang M, Wang X, Wang Q, Wang Y, Lin J, Sun Y, Li X, Zhang L, Lou $Z$, Wang $J$ et al (2014) Molecular mechanism of SCARB2mediated attachment and uncoating of EV71. Protein Cell. doi:10. 1007/s13238-014-0087-3

Hogle JM, Chow M, Filman DJ (1985) Three-dimensional structure of poliovirus at $2.9 \AA$ resolution. Science 229:1358-1365

Lin YW, Lin HY, Tsou YL, Chitra E, Hsiao KN, Shao HY, Liu CC, Sia C, Chong P, Chow YH (2012) Human SCARB2-mediated entry and endocytosis of EV71. PLoS One 7:e30507

Neculai D, Schwake M, Ravichandran M, Zunke F, Collins RF, Peters J, Neculai M, Plumb J, Loppnau P, Pizarro JC et al (2013) Structure of LIMP-2 provides functional insights with implications for SR-BI and CD36. Nature 504:172-176

Nishimura Y, Shimojima M, Tano Y, Miyamura T, Wakita T, Shimizu H (2009) Human P-selectin glycoprotein ligand-1 is a functional receptor for enterovirus 71. Nat Med 15:794-797

Olson NH, Kolatkar PR, Oliveira MA, Cheng RH, Greve JM, McClelland A, Baker TS, Rossmann MG (1993) Structure of a human rhinovirus complexed with its receptor molecule. Proc Natl Acad Sci USA 90:507-511

Plevka P, Hafenstein S, Harris KG, Cifuente JO, Zhang Y, Bowman VD, Chipman PR, Bator CM, Lin F, Medof ME et al (2010) Interaction of decay-accelerating factor with echovirus 7. J Virol 84:12665-12674

Racaniello VR (2007) Picornaviridae: the viruses and their replication. In: Knipe DM, Howley PM (eds) Fields virology. Lippincott Williams \& Wilkins, Philadelphia, pp 796-839

Rossmann MG (1989) The canyon hypothesis. Hiding the host cell receptor attachment site on a viral surface from immune surveillance. J Biol Chem 264:14587-14590

Rossmann MG (1994) Viral cell recognition and entry. Prot Sci 3:1712-1725

Rossmann MG, Arnold E, Erickson JW, Frankenberger EA, Griffith JP, Hecht HJ, Johnson JE, Kamer G, Luo M, Mosser AG et al (1985) Structure of a human common cold virus and functional relationship to other picornaviruses. Nature 317:145153

Rossmann MG, He Y, Kuhn RJ (2002) Picornavirus-receptor interactions. Trends Microbiol 10:324-331
Shakeel S, Seitsonen JJ, Kajander T, Laurinmaki P, Hyypia T, Susi P, Butcher SJ (2013) Structural and functional analysis of coxsackievirus A9 integrin alphavbeta6 binding and uncoating. J Virol 87:3943-3951

Smith TJ, Kremer MJ, Luo M, Vriend G, Arnold E, Kamer G, Rossmann MG, McKinlay MA, Diana GD, Otto MJ (1986) The site of attachment in human rhinovirus 14 for antiviral agents that inhibit uncoating. Science 233:1286-1293

Tuthill TJ, Groppelli E, Hogle JM, Rowlands DJ (2010) Picornaviruses. Curr Top Microbiol Immunol 343:43-89

Xiao C, Bator Kelly CM, Rieder E, Chipman PR, Craig A, Kuhn RJ, Wimmer E, Rossmann MG (2005) The crystal structure of coxsackievirus A21 and its interaction with ICAM-1. Structure 13:1019-1033

Xiao C, McKinlay MA, Rossmann MG (2011) Design of capsidbinding antiviral agents against human rhinoviruses. In: Agbandje-McKenna M, McKenna R (eds) RSC Biomolecular Sciences Series, No 21, Structural Virology. Royal Society of Chemistry, London, pp 321-339

Yamayoshi S, Koike S (2011) Identification of a human SCARB2 region that is important for enterovirus 71 binding and infection. J Virol 85:4937-4946

Yamayoshi S, Yamashita Y, Li J, Hanagata N, Minowa T, Takemura T, Koike S (2009) Scavenger receptor B2 is a cellular receptor for enterovirus 71. Nat Med 15:798-801

Yamayoshi S, lizuka S, Yamashita T, Minagawa H, Mizuta K, Okamoto M, Nishimura H, Sanjoh K, Katsushima N, Itagaki Tet al (2012) Human SCARB2-dependent infection by coxsackievirus A7, A14, and A16 and enterovirus 71. J Virol 86:5686-5696

Yamayoshi S, Ohka S, Fujii K, Koike S (2013) Functional comparison of SCARB2 and PSGL1 as receptors for enterovirus 71. J Virol 87:3335-3347

Yip CC, Lau SK, Woo PC, Yuen KY (2013) Human enterovirus 71 epidemics: what's next? Emerg Health Threats J 6:19780

Zachos C, Blanz J, Saftig P, Schwake M (2012) A critical histidine residue within LIMP-2 mediates $\mathrm{pH}$ sensitive binding to its ligand beta-glucocerebrosidase. Traffic 13:1113-1123

Zhang P, Mueller S, Morais MC, Bator CM, Bowman VD, Hafenstein S, Wimmer E, Rossmann MG (2008) Crystal structure of CD155 and electron microscopic studies of its complexes with polioviruses. Proc Natl Acad Sci USA 105:18284-18289 